Published in final edited form as:

Lung. 2004 ; 182(4): 227-240.

\title{
Lavage Administration of Dilute Surfactant in a Piglet Model of Meconium Aspiration
}

\author{
Joan Meister ${ }^{1}$, Venkataraman Balaraman ${ }^{1}$, Malia Ramirez ${ }^{1}$, Catherine F. T. Uyehara ${ }^{2}$, Jeffrey \\ Killeen ${ }^{3}$, Tercia $\mathrm{Ku}^{2}$, Donald Person ${ }^{2}$, and David Easa ${ }^{1}$ \\ 1 Clinical Research Center and Department of Pediatrics, John A. Burns School of Medicine, \\ University of Hawaii and Kapiolani Medical Center for Women and Children, Honolulu, Hawaii \\ 96826, USA; \\ 2 Department of Clinical Investigation, Tripler Army Medical Center, TAMC, Hawaii 96850, USA; \\ 3 Department of Pathology, John A Burns School of Medicine, University of Hawaii and Kapiolani \\ Medical Center for Women and Children, Honolulu, Hawaii 96826, USA
}

\begin{abstract}
Maldistribution of exogenous surfactant may preclude any clinical response in acute lung injury associated with surfactant dysfunction. Our previous studies have shown the effectiveness of surfactant lavage after homogenous lung injury. The present study utilizes a histologically confirmed non-homogeneous lung injury model induced by saline lung-lavage followed by meconium injected into a mainstem bronchus. Piglets were then treated with Infasurf® or Exosurf® by lavage (ILAVAGE, $n=7$; E-LAVAGE, $n=5$ ) or bolus (I-BOLUS, $n=8$; E-BOLUS, $n=5$ ), or went untreated (CONTROL, $n=4)$. Lavage administration utilized a dilute surfactant $(35 \mathrm{ml} / \mathrm{kg}$; $4 \mathrm{mg}$ phospholipid/ $\mathrm{ml}$ ) instilled into the lung, followed by gravity drainage. The retained doses of the respective surfactant in the lavage and bolus groups were similar. Results showed that the surfactant distribution was more uniform in the lavage groups compared to the bolus groups. Significant and consistent increases in $\mathrm{PaO}_{2}$ were observed in the lavage groups compared to the bolus groups and the controls. $\mathrm{PaO}_{2}(\mathrm{mmHg})$ at $240 \mathrm{~min}$ posttreatment: I-LAVAGE $=297 \pm 54$, E-LAVAGE $=280 \pm 57$; I-BOLUS $=139 \pm 31 ; \mathrm{E}-\mathrm{BOLUS}=152 \pm 29 ; \mathrm{C}=119 \pm 73$ (mean $\pm \mathrm{SEM})$. Other improved pulmonary function parameters favored lavage administration. We conclude that better surfactant distribution achieved by lavage administration can be more effective than bolus administration in this type of nonhomogeneous lung injury.
\end{abstract}

\section{Keywords}

Drug administration technique; Lung injury

\section{Introduction}

Meconium aspiration syndrome (MAS) continues to be a principal cause of neonatal respiratory distress. Despite prophylactic oropharyngeal suctioning of infants delivered with meconiumstained amniotic fluid, the incidence of MAS varies widely (1.7\%-35.8\%) [5,33,37]. In its severest form, MAS results in a vicious cycle of hypoxemia, hypercapnia, acidosis, and death $[1,5,29]$. A variety of therapeutic interventions have been used to manage these infants including supplemental oxygen, mechanical ventilation, vasodilator agents such as nitric oxide

Correspondence to: Venkataraman Balaraman, 1319 Punahou Street, Room 750, Honolulu, HI 96826, USA; email:VBalaraman@kapiolani.org. 
and exogenous surfactant and when all else fails, extracorporeal membrane oxygenation (ECMO) $[10,14]$. Nevertheless, reported mortality rates in MAS are as high as 37\% [5].

In addition to mechanical obstruction of the airways and chemical pneumonitis [34], surfactant dysfunction plays a role in the pathophysiology of MAS [4,8,24,32]. To be sure, meconium has been shown to inactivate surfactant both in vitro $[4,24]$ and in vivo $[8,32]$. This has been the basis for exogenous surfactant administration in this disorder. Accordingly, animal [6,25$27,30-32,38]$ and human $[1,12,17,18,22]$ studies have addressed the question of exogenous surfactant treatment in MAS. While the results in animal studies were promising, only one randomized trial of bolus exogenous surfactant has been reported in infants with MAS [12]. The results of this study did demonstrate some benefits of surfactant treatment for MAS.

In the past 10 years, several investigators [6,11,18,25,27], including our group [2,3] have reported on a new administration technique for surfactant called "lavage administration." Unfortunately, there are significant differences in the administration technique amongst the studies. Our technique utilized a large volume of surfactant that was initially administered into the lung by gravity, followed immediately by gravity drainage of excess fluid. The rationale behind our technique is that uniform lung distribution of surfactant is facilitated by a large volume [35] while simultaneously removing alveolar debris.

In this study, we hypothesized that, given the same dose of surfactant, lavage administration would be more effective than bolus in a meconium-induced lung injury model. We also hypothesized that the efficacy of lavage surfactant would be greater when using a proteincontaining surfactant as compared to a non-protein preparation. To this end, we created a novel model of acute lung injury in neonatal piglets using a combination of repeated saline lung lavage followed by local instillation of meconium into one lung, which resulted in a nonhomogenous lung injury.

\section{Materials and Methods}

\section{Animal Preparation}

This study was approved by the Institutional Animal Care and Use Committee of Tripler Army Medical Center and was in compliance with the USDA Animal Welfare Act and National Research Council's Guide for the Care and Use of Laboratory Animals. Twenty-nine piglets (19 female, 10 male) aged 5-7 days were utilized for these experiments. They were obtained from a local farm on the morning of each experiment. The animals' weights ranged from 1.45$2.65 \mathrm{~kg}$. Anesthesia was induced with intraperitoneal pentobarbital $(30 \mathrm{mg} / \mathrm{kg}$; Wyeth Laboratories, Philadelphia, PA). The animals were then orotracheally intubated with a $4.0 \mathrm{~mm}$ cuffed endotracheal tube (ETT). The lungs were inflated with $100 \mathrm{ml}$ of air to prevent atelectasis and the piglets were then placed on a VIP Bird ventilator (Bird Products Corp., Palm Springs, CA). Initial settings were $\mathrm{FiO}_{2}=0.21$, ventilator rate $=40$ breaths $/ \mathrm{min}$, positive endexpiratory pressure (PEEP) $=5 \mathrm{~cm} \mathrm{H}_{2} \mathrm{O}$, positive inspiratory pressure (PIP) adjusted to maintain End-Tidal $\mathrm{CO}_{2}$ (Hewlett-Packard 47210A, Palo Alto, CA) between 40-45 mmHg. Anesthesia was maintained with hourly or more frequent administration of intravenous pentobarbital $(2.5-5 \mathrm{mg} / \mathrm{kg} / \mathrm{dose})$. Core body temperature, monitored via a rectal probe, was maintained at $37.5-38.5^{\circ} \mathrm{C}$ using heating pads. A femoral artery catheter was placed to monitor blood pressure and allow for arterial blood sampling. A right atrial catheter was placed to monitor central venous pressure (CVP) and to allow for venous blood sampling. These catheters were connected to pressure transducers (Hewlett Packard 66\#M1176A6). A femoral venous catheter was placed to allow for administration of medications and continuous infusion of normal saline $(100 \mathrm{ml} / \mathrm{kg} /$ day $)$. 
Model

Once the animals were prepared as described above, the $\mathrm{FiO}_{2}$ was increased to 1 . The animals were paralyzed with $0.6 \mathrm{mg}$ intravenous Pancuronium (Astra Pharmaceutical, Westborough, MA) which was maintained for the rest of the experimental period $(0.3 \mathrm{mg} /$ dose every hour or more frequently as needed). The PEEP remained at $5 \mathrm{~cm} \mathrm{H}_{2} \mathrm{O}$ and the tidal volume (VT) was adjusted to attain a $\mathrm{PaCO}_{2}$ of between $35-45 \mathrm{mmHg}$. This VT was then maintained throughout the rest of the experimental period by adjusting the PIP. Initial lung injury was induced via a sequential series of saline lung lavages performed 6 minutes apart, as described previously [3]. Each lavage lasted between 90 and 120 seconds. The saline lavages were continued until the $\mathrm{PaO}_{2}$ measurement was $<80 \mathrm{mmHg}$, and remained thus for 20 minutes. A 60-minute observation period followed during which time hemodynamic and pulmonary function parameters were monitored every 30 minutes.

At the end of this 60-minute observation period, the ETT cu. was deflated and the ETT advanced into the mainstem bronchus. The cu. was then reinflated and $1.5 \mathrm{ml} / \mathrm{kg}$ of a $44 \%$ meconium slurry, prepared as previously described [28], was administered into the bronchus via an 8 Fr. feeding catheter inserted through the ETT. The cu. was then deflated, the ETT pulled back to its original position, and the cu. reinflated. After a 30-minute observation period hemodynamic and pulmonary function parameters were recorded. This was defined as Sick.

At this point the piglets either remained untreated (Control $n=4)$ or were placed in one of four treatment groups described below. This was followed by a 4-hour observation period with hemodynamic and pulmonary function measurements obtained every 30 minutes. At the end of the 4 hours, the piglets were humanely euthanized with $1.5 \mathrm{ml}$ Beuthanasia-Dâ (HoffmanLaRoche, MO).

\section{Treatment Groups}

Infasurf® (Calfactant, ONY Inc., Amherst, NY) administered by lavage (I-LAVAGE $n=7$ ), Infasurf administered by bolus (I-BOLUS $n=8$ ), Exosurf® (Colfosceril; Cetyl Alcohol; Tyloxapol, Glaxo Wellcome, Research Triangle, NC) administered by lavage (E-LAVAGE $n=5$ ), or Exosurf administered by bolus (E-BOLUS $n=5$ ).

\section{Surfactant Preparation}

A diluted preparation of Infasurf $(4 \mathrm{mg} / \mathrm{ml})$ was utilized for the I-LAVAGE experiments. In I-BOLUS experiments, in accordance with clinical practice, a fixed volume of surfactant was administered using an average volume of $3 \mathrm{ml} / \mathrm{kg}$. Thus, in order to administer the same dose of surfactant as in the I-LAVAGE group, the concentration of Infasurf varied between 5 and $9.3 \mathrm{mg} / \mathrm{ml}$. Infasurf is a bovine surfactant containing phospholipids and apoprotein B and C. In contrast, we used the same dilution $(4 \mathrm{mg} / \mathrm{ml})$ for both the E-LAVAGE and E-BOLUS groups. The volume of surfactant in the E-BOLUS group was matched to the retained surfactant volume in the E-LAVAGE group. Exosurf is an artificial non-protein-containing surfactant.

\section{Surfactant Administration}

A volume of $35 \mathrm{ml} / \mathrm{kg}$ of surfactant (Infasurf or Exosurf) was used for the Lavage groups. Administration was performed by gravity-assisted lavage through tubing connected to the ETT after disconnecting the piglet from the ventilator. Instillation was from a height $60 \mathrm{~cm}$ above the piglets' head immediately followed by passive gravity-assisted drainage accomplished by lowering the tubing $60 \mathrm{~cm}$ below the piglets' head. While not quantified for meconium content, the surfactant fluid return was consistently meconium stained. The entire procedure lasted no more than 120 seconds after which the piglet was reconnected to the ventilator. 
For bolus administration, the total volume was administered in two aliquots with the piglet in the horizontal position through a small suction catheter advanced to just beyond the tip of the ETT. The catheter was inserted through a one-way adapter connecting the endotracheal tube to the ventilator tubing (Bodie Neo2-Safe valve, BNB Medical Technologies, Inc., Orangevale, CA), which was used to maintain end-expiratory pressure during surfactant administration. One aliquot was administered with the piglet held left side down while the other aliquot was administered with the piglet right side down. After each aliquot was instilled, the piglet was ventilated for 30 seconds while being maintained with the appropriate side down. Upon completion of the procedure, the piglet was placed in the original supine position.

\section{Pulmonary Function}

Respiratory flow and airway pressures were monitored continuously with a low dead-space pneumotachometer (\#8410: Hans Rudolph, Kansas City, MO). An 8 French fluid-filled catheter was placed in the lower third of the esophagus for measurement of esophageal pressure (Pes). The placement was validated by occlusion. Digitized signals for flow, VT, airway pressure and Pes were collected with a PC-based data acquisition system (AT-CODAS; Dataq Instruments, Akron, Ohio) to measure dynamic pulmonary compliance (Cdyn) and lung resistance (RL). Functional residual capacity (FRC) was measured by the helium dilution technique (Equilibrated Bio Systems, Inc., Melville, NY). Arterial blood gases and arterial/ venous co-oximeter measurements were also obtained every 30 minutes for the duration of the experiment.

\section{Hemodynamic Measurements}

Heart rate (HR), central venous pressure (CVP) and mean arterial pressure (MAP), were continuously monitored throughout the experiment.

\section{Retained Surfactant Fluid Volume (lavage groups only)}

This volume was calculated by subtracting the volume of the gravity drained surfactant fluid return from the initial volume of surfactant administered.

\section{Quasi-static Pressure Volume (PV)Curves}

After euthanasia, the piglets were disconnected from the ventilator for 5 minutes to allow the lungs to collapse. The lungs were then subjected to inflation in $5 \mathrm{~cm} \mathrm{H}_{2} \mathrm{O}$ increments at pressures from 5 to $35 \mathrm{~cm} \mathrm{H} 2 \mathrm{O}$. Volume measurements were taken after 30 seconds of equilibration at each pressure. Deflation volumes were measured in the same way, also at 5 $\mathrm{cm} \mathrm{H}_{2} \mathrm{O}$ increments from 35 to $0 \mathrm{~cm} \mathrm{H}_{2} \mathrm{O}$.

\section{Surfactant Distribution}

Colored microspheres (E-Z Trac, Improtech International, Los Angeles, CA) obtained in a suspension of aqueous solution, with a diameter of $15 \mu \mathrm{m}$ were utilized. A total of $1.5 \times 10^{5}$ microspheres were added to each $\mathrm{ml}$ of surfactant preparation. After the piglet was euthanized, the lungs were inflated to $20 \mathrm{~cm} \mathrm{H}_{2} \mathrm{O}$ pressure and the lung/heart/trachea block was removed and frozen by immersion into liquid nitrogen. The lungs were then systematically cut into 53 pieces, labeled and weighed, and then sent for counting and analysis by a proprietary company (Improtech International, Los Angeles, CA). Surfactant distribution in each lung piece, as indicated by the microsphere count, was calculated by dividing the number of microspheres in each lung piece (corrected for weight in grams) by the expected number, defined as the total microsphere count in the lung divided by the total lung weight in grams. The calculated ratios for all lung pieces were then plotted. 


\section{Lung Pathology}

After euthanasia, Quasi-static PV curves were obtained and bronchoalveolar lavage was performed. Following this, the heart and lungs were removed en bloc. The right ventricle was cannulated and a catheter was advanced into the main pulmonary artery. An incision was made in the left atrium to allow escape of infused fluid. Seventy-five milliliters of normal saline was slowly infused through the catheter followed by $100 \mathrm{ml}$ of $10 \%$ buffered formalin in order to fix the pulmonary vasculature. After a minimum of 24 hours, the gross structure of the heart and lung was examined. Subsequently, 3 sections from each lung lobe were prepared, embedded in Ameraffin, and stained with hematoxylin and eosin for review by a pathologist blinded to the treatment groups. A four point $(0,1,2,3)$ scoring system, modified from Lewis et al. [12], assessed each section for polymorphonuclear lymphocyte infiltration, atelectasis, edema, necrosis, hemorrhage, and the presence of meconium. A total score for each lung was then assigned based on the sum of the individual scores.

\section{Data Analysis}

A computer software package (SigmaStat, SPSS Inc., Chicago, IL) was used for statistical analysis. Normality was tested with the Kolmogorov-Smirnov test and non-normally distributed data were ranked prior to analysis. Differences within and between groups were determined using two-way ANOVA for repeated measures. When significant differences were detected, the Student Neuman-Keuls post-hoc test was used. For all results, $p<0.05$ was considered significant. Data in all figures and tables are expressed as mean \pm standard error of the mean (SEM). Surfactant distribution data were analyzed for normal distribution through a curve-fitting equation for Gaussian distribution (Graph-Pad Prism, Intuitive Software for Science, San Diego, CA).

\section{Results}

Twenty-nine neonatal piglets (19 female, 10 male) were studied. There were no differences between the groups for body weight or age. All results are reported as either the mean or mean \pm SEM.

\section{Induction of Lung Injury}

The average number of saline lung lavages required to reach blood gas criteria prior to meconium instillation was similar among all groups (I-LAVAGE $=8.9$, E-LAVAGE $=9.4$, IBOLUS $=7.8$, E-BOLUS $=7.6$, and Control $=8$ ).

\section{Retained Surfactant Fluid Volume and Dose}

The DPPC dose was matched between I-LAVAGE and I-BOLUS groups, as well as between the Exosurf groups. The I-LAVAGE group retained $4.8 \pm 0.6 \mathrm{ml} / \mathrm{kg}$, corresponding to $19.4 \pm$ $2.6 \mathrm{mg} / \mathrm{kg}$ DPPC, while the I-BOLUS group received a volume of $3.0 \pm 0.2 \mathrm{ml} / \mathrm{kg}$, corresponding to $19.3 \pm 2.9 \mathrm{mg} / \mathrm{kg}$ DPPC. There were no differences between the two groups in the dose administered. The E-LAVAGE and E-BOLUS groups were identical for both volume and dose $(11 \pm 0.9 \mathrm{ml} / \mathrm{kg}$ and $44 \pm 3.4 \mathrm{mg} / \mathrm{kg}$ DPPC $)$. The disparity between the retention of Infasurf and Exosurf administered by lavage has previously been observed [3], accounting for the differences in doses between I-LAVAGE and E-LAVAGE groups.

\section{Pulmonary Function}

There was no improvement in oxygenation in either Control or I-BOLUS groups. In contrast, although the E-BOLUS, I-LAVAGE and E-LAVAGE groups demonstrated improvement in oxygenation over time, only the latter two groups were different when compared to Controls (Fig. 1, Table 1). $\mathrm{PaO}_{2}$ values at 240 minutes were I-LAVAGE $=297 \pm 54$; E-LAVAGE $=280$ 
\pm 57 ; I-BOLUS $=139 \pm 31 ;$ E-BOLUS $=152 \pm 29 ;$ and Control $=119 \pm 73 \mathrm{mmHg}$. No differences were found when comparing I-LAVAGE to E-LAVAGE. Values for $\mathrm{PaCO}_{2}$ at 240 minutes were I-LAVAGE $=48 \pm 4$; E-LAVAGE $=47 \pm 2$; I-BOLUS $=52 \pm 4 ;$ E-BOLUS $=$ $54 \pm 5$; and Control $\mathrm{L}=67 \pm 8$. Despite numerical trends toward lower levels in both of the Lavage groups with time, no differences were found within or between groups (Table 1). With regard to quasistatic PV curves, although Lavage groups tended to have higher volumes at 35 $\mathrm{cm} \mathrm{H}_{2} \mathrm{O}$ pressure than the Bolus and Control groups, there were no differences between groups (Fig. 2). There were no significant differences found in FRC, Cdyn, and RL during the 4-hour observation period within or between groups ( 240 min data shown in Table 1).

\section{Surfactant Distribution}

A total of 9 experiments utilized microspheres for surfactant distribution; 5 were from Lavage groups (3 Infasurf, 2 Exosurf) and 4 from the Bolus groups (3 Infasurf, 1 Exosurf). Since there were no apparent differences between surfactant preparations and the numbers were small, the results of all distribution studies were combined for Lavage as well as for Bolus groups. While both curves fit into the Gaussian equation, suggesting data normality, the mean value for Lavage $(0.94, \mathrm{r} 2=0.71)$ was different than for Bolus $(0.56, \mathrm{r} 2=0.43)(p<0.05)$, documenting more uniform distribution with lavage surfactant administration (Fig. 3).

\section{Hemodynamic Parameters}

MAP significantly decreased over time in the Control group, but remained unchanged in any of the treatment groups (data not shown). However, no clinically significant differences were found among groups in HR, MAP, and CVP.

\section{Lung Pathology}

Histopathological sections were made on 13 piglets (4 Lavage, 5 Bolus, 4 Control) and the majority of histopathology scores ranged between 1 and 3. Interestingly, despite the meconium administration into the mainstem bronchus, there were no differences between the histopathology scores of the right and left lung, and between treatment groups. The most striking and consistent finding was the extreme variation in the degree of lung injury found in adjacent lung segments (for most lung segments, severity scores ranged at least 2 out of 4). Thus, neighboring areas of minimally affected lung were adjacent to those showing an extreme degree of inflammation, the presence of meconium and fibrin debris, atelectasis, and interstitial edema (Fig. 4).

\section{Discussion}

To our knowledge, this is the first study to demonstrate that, when comparing an equivalent dose of surfactant, lavage administration is superior to bolus in improving oxygenation in a non-homogenous meconium-induced acute lung injury model. This was demonstrated with a synthetic, non-protein-containing surfactant as well as an animal-based protein-containing surfactant. We attribute these results to both a more uniform surfactant distribution, as well as to the simultaneous removal of alveolar debris from the lung in the Lavage groups.

Our model of lung injury was unique. In prior studies, meconium was simply administered directly into the normal lung of an animal, including piglets, rats, rabbits, and monkeys $[6,8$, 25-27,30-32]. Using this technique, both Cochrane et al. [10] and 1 Sun et al. [9] suggested that the meconium was unevenly distributed in the lung, leaving certain residual lung regions that appeared well expanded and even normal, presumably because they were beyond the reach of the meconium. In contrast, we created a complex nonhomogenous lung injury model by first performing multiple saline lung lavages to deplete surfactant stores and induce an initial uniform background lung injury. Then, meconium was administered into a mainstem bronchus 
in order to further injure the lung non-uniformly. We believe this created a more extensive lung injury than if we had utilized the standard models of meconium aspiration described above. To be sure, our model may be more relevant to the human situation when infants with meconium aspiration syndrome are vigorously ventilated over days, thus aggravating the initial lung injury [9].

We were surprised by the modest improvement in oxygenation seen in the E-BOLUS group as compared to the I-BOLUS and Control groups. Perhaps this was a result of the higher DPPC dose and/or the higher volume of surfactant in the E-BOLUS group. Other animal studies utilizing bolus surfactant in MAS have been more promising. Sun et al. [19,21] published several studies that showed rapid improvement in oxygenation after the administration of bolus surfactant in their animal models of MAS. The surfactant doses utilized in these studies were between 100 and $200 \mathrm{mg} / \mathrm{kg}$, which mimicked the doses generally used in the treatment of neonatal Respiratory Distress Syndrome. Importantly, they found a more pronounced and sustained effect at the higher dose of surfactant [30]. This may explain the lack of appreciable effect of bolus in our study, since our bolus dose was about 10-25\% of those used by Sun et al. Nevertheless, dose may not be the only factor related to the lack of effect of bolus surfactant in MAS. In the extensive study of Wiswell et al. [13] the investigators did not show any benefits from high doses of several surfactant preparations in MAS.

Other explanations for the inconsistent results of bolus surfactant in these experimentally induced MAS studies include an ongoing inactivation of surfactant by meconium [24,34], and/ or the uneven lung distribution of surfactant when administered by bolus [19,21]. A lavage approach to surfactant administration was consequently described that would theoretically address these concerns. Indeed, recent animal studies [6,25-27] have demonstrated that surfactant administered by lavage improves oxygenation in experimentally induced MAS, while simultaneously removing meconium from the lung $(41.5 \%-68.9 \%$ recovery rate). In addition, there are two studies evaluating the use of surfactant lavage in newborn infants with MAS. Although, the techniques used in these studies were different, both the studies reported promising results $[18,37]$.

Interestingly, the lavage technique used in the above studies varied greatly. Differences included the administration volumes (range: $5-35 \mathrm{ml} / \mathrm{kg}$ ), the surfactant instillation and fluid recovery methods (active versus passive), and the number of lavages performed (range: 1-4). Despite these major differences in technique, all studies showed improvements in oxygenation after lavage surfactant. This does not preclude the need to better define an optimal lavage administration technique. Regarding our specific method, we have previously reported that piglets administered surfactant by lavage have tolerated the procedure well, with only transient perturbations in hemodynamics and organ blood flow $[11,16]$.

The advantages of the lavage technique could also help explain the unexpected beneficial effects in the E-LAVAGE group, confirming our previous experience with lavage Exosurf $[2,3]$. This non-protein-containing surfactant preparation has not been shown to be as effective as protein-containing surfactants such as 2 Survanta and Infasurf [7,15]. Thus, the improvement in oxygenation observed in this group may have been due to the combined effect of improved distribution and removal of meconium during the lavage procedure.

In summary, based on a review of the literature, which is supported by the results of this study, and the general experience in most NICU's, surfactant treatment has become a standard treatment for severe MAS. Although individual response to bolus surfactant may be quite variable, this may in part be due to this method of administration. With the introduction of the lavage technique, there is now a need to better define the optimal approach to surfactant administration in the MAS. 
It may be that the best approach to surfactant administration combines the use of both lavage followed by bolus administration. The rationale behind this approach is to first reduce the extent of lung injury by removing as much meconium as possible, while simultaneously administering surfactant to the lung. Then, bolus surfactant would insure that a sufficient dose of surfactant remains in the lung to counter the surfactant inhibitory effect of meconium, thus allowing for a more sustained therapeutic effect [23]. A variation of this approach, described by Cochrane et al. [6], initially utilized up to 3 sequential surfactant lavages using a diluted surfactant. This was followed by a final dose with either a high dose lavage or a high dose bolus surfactant treatment. This treatment regimen was also reported in a Phase I/II study in newborn infants with MAS [37]. Unfortunately, the results of the human study were not as promising as the earlier animal studies. A similar approach to surfactant administration (initial lower dose followed by a higher dose) was described by Gommers et al. [13] with encouraging results.

The ultimate role of lavage surfactant in the management of MAS remains to be determined in future studies. One goal should be to determine the optimal administration technique for lavage surfactant in order to optimize surfactant distribution, most efficiently remove alveolar debris, and do so with minimal adverse effects. Although, the technique described by us appears to be very invasive, the incidences of short-term adverse effects are very transient and overall the treatment is well tolerated by animals who have severe pulmonary dysfunction at the time of treatment. Nevertheless, there will be concerns with the 2 minutes of non-ventilation during the lavage procedure when considering the applicability of this technique to humans. Since this may be a barrier to acceptance, the question of safety must await results of pilot studies in humans.

Finally, our results support the continued research in standardizing the lavage technique for treatment of MAS. It would also appear that treatment by this technique would be most beneficial early in the course of the disease before secondary lung injury and dysfunction develop.

\section{Acknowledgements}

This manuscript was supported by a Research Centers in Minority Institutions Award, P20 RR/AI 11091, from the National Center for Research Resources, National Institutes of Health; the U.S. Army Medical Command; the Leahi Fund of the Hawaii Community Foundation; and Kapiolani Medical Center for Women and Children. The opinions and assertions contained herein are the private views of the authors and are not to be construed as reflecting the views of the Department of the Army, the Department of Defense, or the U.S. Government. The assistance of Ms. Jessica Busch in the preparation of the final manuscript is appreciated.

\section{References}

1. Auten RL, Notter RH, Kendig JW, Davis JM, Shapiro DL. Surfactant treatment of full-term newborns with respiratory failure. Pediatrics 1991;87:101-107. [PubMed: 1984603]

2. Balaraman V, Hashiro G, Sood SL, et al. Physiologic response and lung distribution of lavage versus bolus exosurf in piglets with acute lung injury. Am J Respir Crit Care Med 1996;153:1838- 1843. [PubMed: 8665043]

3. Balaraman V, Meister J, Ku TL, et al. Lavage administration of dilute surfactants after acute lung injury in neonatal piglets. Am J Resp Crit Care Med 1998;158:12-17. [PubMed: 9655700]

4. Chen CT, Toung TJK, Rogers MC. Effect of intra-alveolar meconium on pulmonary surface tension properties. Crit Care Med 1985;13:233-236. [PubMed: 3979070]

5. Cleary GM, Wiswell TE. Meconium-stained amniotic fluid and the meconium aspiration syndrome: an update. Pediatr Clin North Am 1998;45:511-529. [PubMed: 9653434]

6. Cochrane CG, Revak SD, Merritt TA, et al. Bronchoalveolar lavage with KL4-surfactant in models of meconium aspiration syndrome. Pediatr Res 1998;44:705-715. [PubMed: 9803452] 
7. Cummings JJ, Holm BA, Hudak ML, et al. A controlled clinical comparison of four different surfactant preparations in surfactant-deficient preterm lambs. Am Rev Respir Dis 1992;145:999-1004. [PubMed: 1586078]

8. Davey AM, Becker JD, Davis JM. Meconium aspiration syndrome: physiological and inflammatory changes in a newborn piglet model. Pediatr Pulmonol 1993;16:101-108. [PubMed: 8367215]

9. Duara S, Gewitz MH, Fox WW. Use of mechanical ventilation for clinical management of persistent pulmonary hypertension of the newborn. Clin Perinatol 1998;11:641-652. [PubMed: 6435924]

10. Durand M, Snyder JR, Gangitano E, Wu PYK. Oxygenation index in patients with meconium aspiration: conventional and extracorporeal membrane Oxygenation therapy. Crit Care Med 1990;8:373-377. [PubMed: 2318047]

11. Eijking EP, Gommers D, So KL, Vergeer M, Lachmann B. Surfactant treatment of respiratory failure induced by hydrochloric acid aspiration in rats. Anesthesiology 1993;78:1145-1151. [PubMed: 8512108]

12. Findlay RD, Taeusch HW, Walther FJ. Surfactant replacement therapy for meconium aspiration syndrome. Pediatrics 1996;97:48-52. [PubMed: 8545223]

13. Gommers D, Eijking EP, So KL, van't Veen A, Lachmann B. Bronchoalveolar Lavage with a diluted surfactant suspension prior to surfactant instillation improves the effectiveness of surfactant therapy in experimental acute respiratory distress syndrome(ARDS). Intensive Care Med 1998;24:494-500. [PubMed: 9660267]

14. Graves ED 3rd, Loe WE, Redmond CR, Falterman KW, Arensman RM. Extracorporeal membrane oxygenation as treatment of severe meconium aspiration syndrome. South Med J 1989;82:696-698. [PubMed: 2734633]

15. Halliday HL. Overview of clinical trials comparing natural and synthetic surfactants. Biol Neonate 1995;67(suppl 1):32-47. [PubMed: 7647157]

16. Ku T, Meister J, Balaraman V, et al. Regional blood flow (RBF) in piglets with acute lung injury (ALT) after lavage surfactant administration (abstract). Am J Respir Crit Care Med 1999;159:A595.

17. Khammash H, Perlman M, Wojtulewicz J, Dunn M. Surfactant therapy in full-term neonates with severe respiratory failure. Pediatrics 1993;92:135-139. [PubMed: 8516059]

18. Lam BCC, Yeung CY. Surfactant lavage for meconium aspiration syndrome: a pilot study. Pediatrics 1999;103:1014-1018. [PubMed: 10224181]

19. Lewis JF, Jobe AH. Surfactant and the adult respiratory distress syndrome. Am Rev Respir Dis 1993;147:218-233. [PubMed: 8420422]

20. Lewis JF, McCaig L. Aerosolized versus instilled exogenous surfactant in a nonuniform pattern of lung injury. Am Rev Resp Dis 1993;148:1187-1193. [PubMed: 8239152]

21. Lewis JF, Tabor B, Ikegami M, et al. Lung function and surfactant distribution in saline lavaged sheep given instilled vs. nebulized surfactant. J Appl Physiol 1993;74:1256-1264. [PubMed: 8482666]

22. Lotze A, Mitchell BR, Bulas DI, et al. Multicenter study of surfactant (beractant) use in the treatment of term infants with severe respiratory failure. Survanta in Term Infants Study Group. J Pediatr 1998;132:40-47. [PubMed: 9469998]

23. Moller JC, Kohl M, Reiss II, et al. Saline lavage with substitution of bovine surfactant in term neonates with meconium aspiration syndrome (MAS) transferred for extracorporeal membrane oxygenation (ECMO): a pilot study. Crit Care (Lond) 1999;3:19-22.

24. Moses D, Holm BA, Spitale P, Liu M, Enhorning G. Inhibition of pulmonary surfactant function by meconium. Am J Obstet Gynecol 1991;164:477-481. [PubMed: 1992687]

25. Ohama Y, Itakura Y, Koyama N, Eguchi H, Ogawa Y. Effect of surfactant lavage in a rabbit model of meconium aspiration syndrome. Acta Paediatr Jpn 1994;36:236-238. [PubMed: 8091968]

26. Ohama Y, Ogawa Y. Treatment of meconium aspiration syndrome with surfactant lavage in an experimental rabbit model. Pediatr Pulmonol 1999;28:18-23. [PubMed: 10406046]

27. Paranka MS, Walsh WF, Stancombe BB. Surfactant lavage in a piglet model of meconium aspiration syndrome. Pediatr Res 1992;31:625-628. [PubMed: 1635826]

28. Patrinos ME, Balaraman V, Ku T, et al. Promoting meconium clearance from the lungs of the neonatal piglet with asymmetric high frequency oscillation. Pediatr Res 1997;42:342-347. [PubMed: 9284275] 
29. Srinivasan HB, Vidyasagar D. Meconium aspiration syndrome: current concepts and management. Compr Ther 1999;25:82-89. [PubMed: 10091012]

30. Sun B, Herting E, Curstedt T, Robertson B. Exogenous surfactant improves lung compliance and oxygenation in adult rats with meconium aspiration. J Appl Physiol 1994;77:1961-1971. [PubMed: 7836224]

31. Sun B, Curstedt T, Robertson B. Exogenous surfactant improves ventilation efficiency and alveolar expansion in rats with meconium aspiration. Am J Respir Crit Care Med 1996;154:764-770. [PubMed: 8810617]

32. Sun B, Curstedt T, Song GW, Robertson B. Surfactant improves lung function and morphology in newborn rabbits with meconium aspiration. Biol Neonate 1993;63:96-104. [PubMed: 8448260]

33. Sunoo CS, Kosasa TS, Nakayama RT, Hale RW. The incidence of meconium aspiration in Hawaii. Hawaii Med J 1993;52:290-293. [PubMed: 8300401]

34. Tyler DC, Murphy J, Cheney FW. Mechanical and chemical damage to lung tissue caused by meconium aspiration. Pediatrics 1978;62:454-459. [PubMed: 714576]

35. Van der Bleek J, Plotz FB, van Overbeek FM, et al. Distribution of exogenous surfactant in rabbits with severe respiratory failure: the effect of volume. Pediatr Res 1993;34:154-157. [PubMed: 8233717]

36. Wiswell TE, Gannon CM, Jacob J, et al. Delivery room management of apparently vigorous meconium-stained neonate: results of the Multicenter, International Collaborative Trial. Pediatrics 2000;105:1-7. [PubMed: 10617696]

37. Wisell TE, Knight GR, Finer NN, et al. A multicenter, randomized, controlled trial comparing Surfaxin (Lucinactant) lavage with standard care for treatment of meconium aspiration syndrome. Pediatrics 2002;109:1081-1087. [PubMed: 12042546]

38. Wiswell TE, Peabody SS, Davis JM, et al. Surfactant therapy and high-frequency jet ventilation in the management of a piglet model of the meconium aspiration syndrome. Pediatr Res 1994;36:494500. [PubMed: 7816525] 


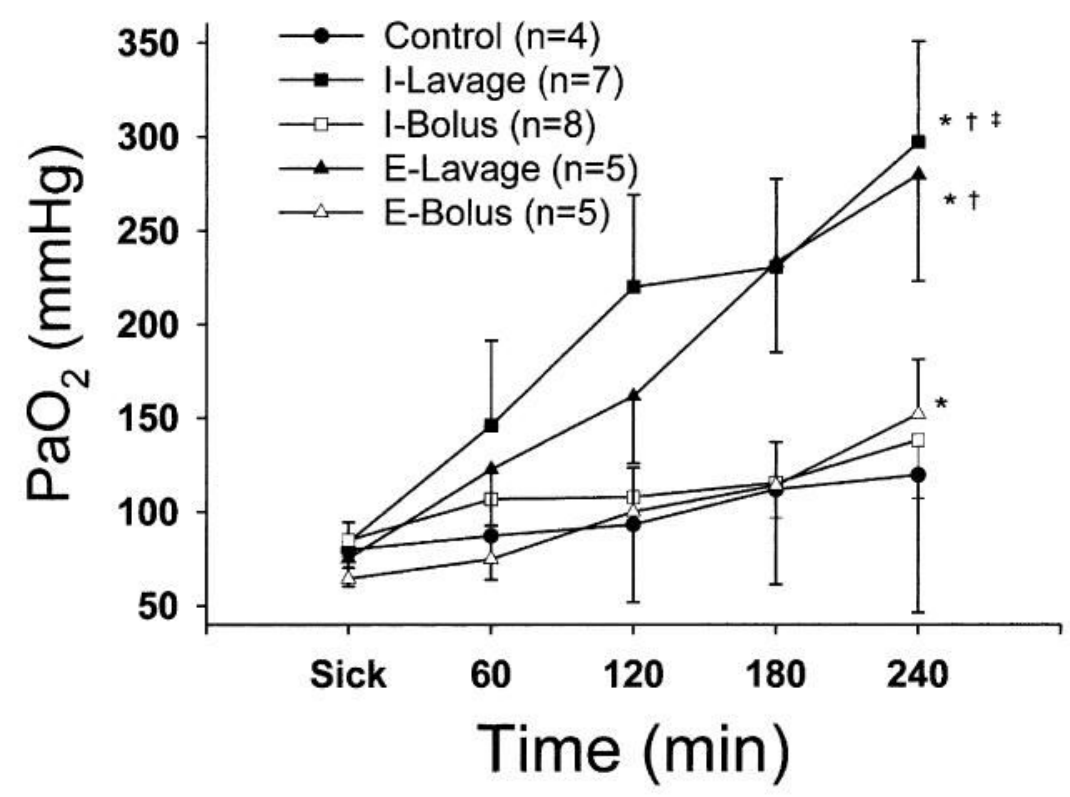

Fig. 1.

$\mathrm{PaO}_{2}$ in control and surfactant-treated groups. Surfactant was administered immediately after Sick measurement. *Different from sick within the group; ${ }^{\dagger}$ different from control; ${ }^{\ddagger}$ different from respective bolus group. 


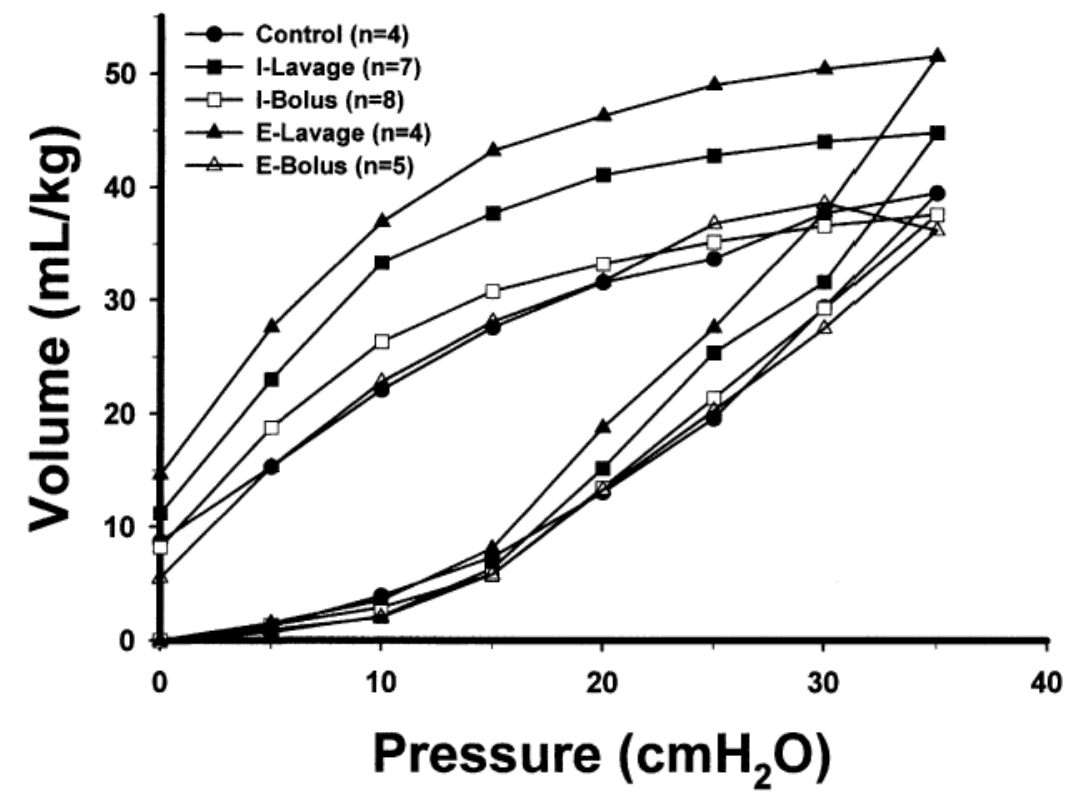

Fig. 2.

Quasi-static pressure-volume curves for control and surfactant-treated groups. Error bars deleted for clarity. The lower portion of the curves represents the inflation component while the upper portion represents the deflation component. 


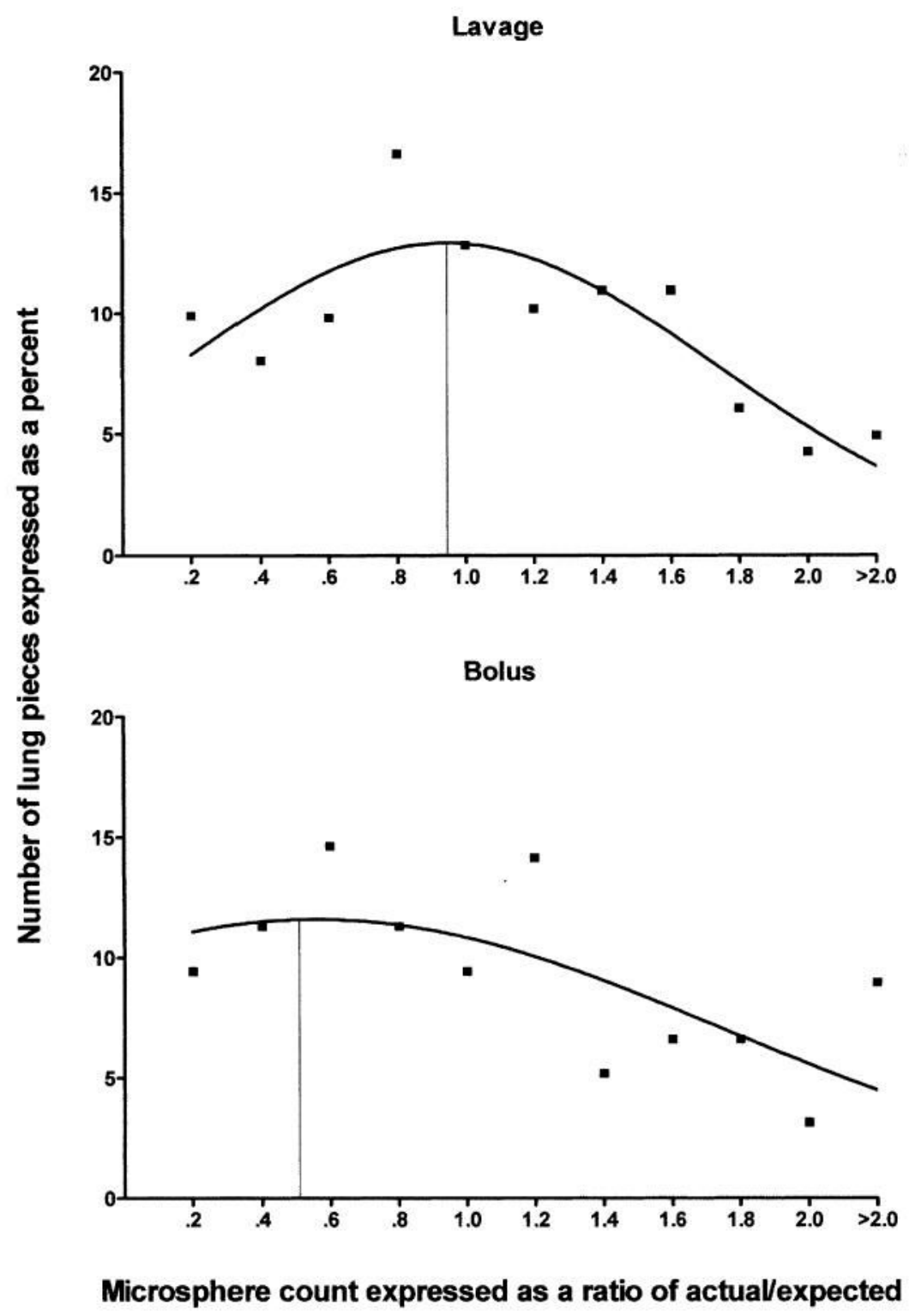

Fig. 3.

Surfactant distribution as measured by colored microspheres. Upper panel showing pooled data from lavage groups ( 5 animals; $n=265$ lung pieces); lower panel showing pooled data from bolus groups ( 4 animals; $n=212$ lung pieces). Microsphere count in each lung piece expressed as ratio of actual/expected in increment intervals of 0.2 on the $x$-axis. The vertical line on the graph represents the mean for the data. 


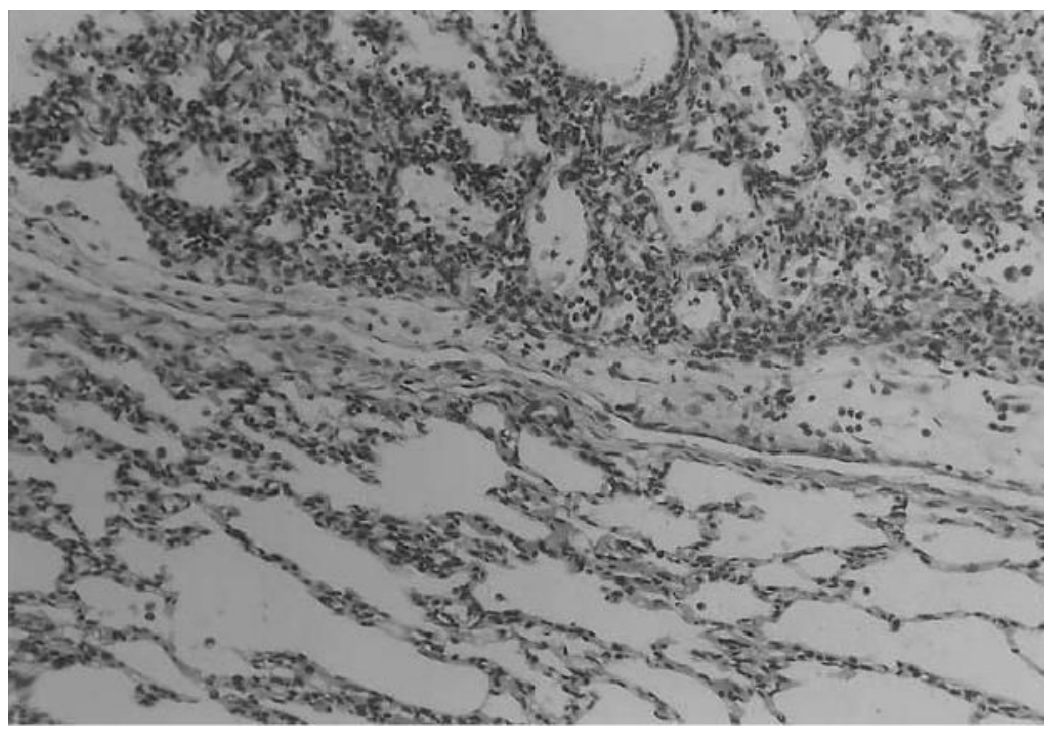

Fig. 4.

Photomicrograph of a representative section of the lung showing adjacent areas of relatively normal-appearing architecture and signs of severe inflammation with neutrophil, infiltration. 
Table 1

Selected pulmonary function parameters

\begin{tabular}{|c|c|c|c|c|c|}
\hline Parameter & Control & I-Lavage & E-Lavage & I-Bolus & E-Bolus \\
\hline $\mathrm{PaO}_{2}(\mathrm{mmHg})$ & $119+73$ & $297+54$ & $280+57$ & $138+31$ & $152+29$ \\
\hline $\mathrm{PaCO}_{2}(\mathrm{mmHg})$ & $67+8$ & $48+4$ & $47+2$ & $52+4$ & $54+5$ \\
\hline $\mathrm{pH}$ & $7.13+0.14$ & $7.31+0.04$ & $7.3+0.01$ & $7.24+0.06$ & $7.31+0.03$ \\
\hline Dynamic compliance $\left(\mathrm{ml} / \mathrm{cm} \mathrm{H} \mathrm{H}_{2} \mathrm{O}\right)$ & $1.03+0.33$ & $2.56+0.67$ & $1.87+0.28$ & $1.92+0.59$ & $1.33+0.12$ \\
\hline Total lung resistance $\left(\mathrm{cmH}_{2} \mathrm{O} / \mathrm{L} / \mathrm{s}\right)$ & $64+8$ & $68+20$ & $37+3$ & $71+18$ & $46+4$ \\
\hline Functional residual capacity $(\mathrm{ml} / \mathrm{kg})$ & $21+2$ & $25+4$ & $24+2$ & $25+2$ & $19+0$ \\
\hline Positive inspiratory pressure & $29+4$ & $21+4$ & $22+1$ & $23+1$ & $23+3$ \\
\hline Mean airway pressure & $11.5+0.7$ & $10.5+1$ & $10.2+0.3$ & $10.3+0.2$ & $15.1+4$ \\
\hline
\end{tabular}

Comparison of pulmonary function and ventilator variables among, Control, I-Lavage, E-Lavage, I-Bolus and E-Bolus groups at 240 min after treatment. All values shown are mean+SE. There were no differences in any of the parameters (two-way ANOVA) except $\mathrm{PaO}_{2}$ as described in the text. 